\title{
Test and Analysis of a New Ductile Shear Connection Design for RC Shear Walls
}

\author{
Sørensen, Jesper Harrild; Hoang, Linh Cao; Olesen, John Forbes; Fischer, Gregor
}

Published in:

Structural Concrete

Link to article, DOI:

$10.1002 /$ suco.201600056

Publication date:

2017

Document Version

Peer reviewed version

Link back to DTU Orbit

Citation (APA):

Sørensen, J. H., Hoang, L. C., Olesen, J. F., \& Fischer, G. (2017). Test and Analysis of a New Ductile Shear Connection Design for RC Shear Walls. Structural Concrete, 18(1), 189-204.

https://doi.org/10.1002/suco.201600056

\section{General rights}

Copyright and moral rights for the publications made accessible in the public portal are retained by the authors and/or other copyright owners and it is a condition of accessing publications that users recognise and abide by the legal requirements associated with these rights.

- Users may download and print one copy of any publication from the public portal for the purpose of private study or research.

- You may not further distribute the material or use it for any profit-making activity or commercial gain

- You may freely distribute the URL identifying the publication in the public portal 


\section{Test and analysis of a new ductile shear connection design for RC shear walls}

\section{Jesper Harrild Sørensen I Linh Cao Hoang I John Forbes Olesen I Gregor Fischer}

Department of Civil Engineering, Technical University of Denmark, Lyngby, Denmark

Correspondence

Jesper Harrild Sørensen, Department of Civil Engineering, Technical University of Denmark, Brovej, Bygning 118, 2800 Kgs. Lyngby,

Denmark.

Email: jhaso@byg.dtu.dk

Funding information

Danish Association for Precast Concrete Elements; COWI Foundation.
This paper presents a new and construction-friendly shear connection for the assembly of precast reinforced concrete shear wall elements. In the proposed design, the precast elements have indented interfaces and are connected by a narrow zone grouted with mortar and reinforced with overlapping U-bar loops. Contrary to conventional shear connections, the planes of the U-bar loops are here parallel to the plane of the wall elements. This feature enables a constructionfriendly installation of the elements without the risk of rebars clashing. The core of mortar inside each U-bar loop is reinforced with a transverse double T-headed bar to ensure transfer of tension between the overlapping U-bars. Push-off tests show that a significantly ductile load-displacement response can be obtained by the new solution as compared to the performance of the conventional keyed shear connection design. The influence of the interface indentation geometry was investigated experimentally and the failure modes in the push-off tests were identified by use of digital image correlation (DIC). For strength prediction, rigid plastic upper-bound models have been developed with inspiration from the observed failure mechanisms. Satisfactory agreement between tests and calculations has been obtained.

\section{KEYWORDS}

concrete plasticity, digital image correlation, ductility, keyed shear connections, robustness

\section{1 | INTRODUCTION}

Structural solutions based on precast concrete elements are often more economically feasible than in situ cast solutions, because precast technology enables a reduction of construction time as well as labor cost. When using precast solutions, the on-site work mostly consists of assembling and connecting the precast elements into an integrated structural system. Hence, connection designs that are constructionfriendly play an important role for the overall cost reduction. It is, however, a challenge to design connections that are easy to construct and at the same time have structural performance (in terms of strength and ductility) which can be compared with that of in situ cast solutions. In cases with unusual structural geometry, it may be necessary to supplement the advantages of precast construction with in situ cast solutions in selected zones. An example of how current precast solutions have been pushed to the limit can be studied in References 1 and 2 that report on the design and construction of a landmark building in Copenhagen, Denmark. The leaning characteristic of the building imposed serious challenges to the design of the shear connections between the precast panels for insurance of overall structural stability.

Currently, structural continuity between precast shear panels is established by use of narrow keyed connections containing overlapping U-bars and grouted with mortar (see Figure 1). However, with this conventional solution, which has been used since the 1960s, it is difficult to obtain full structural continuity because the strength and ductility of 
(a)

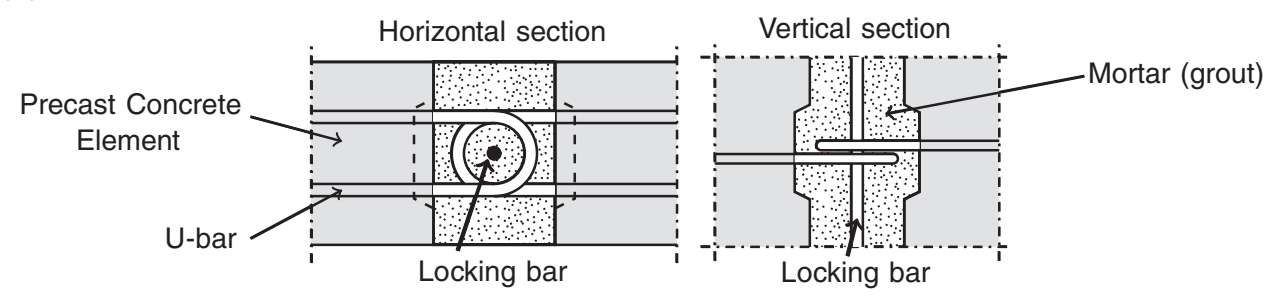

(b)

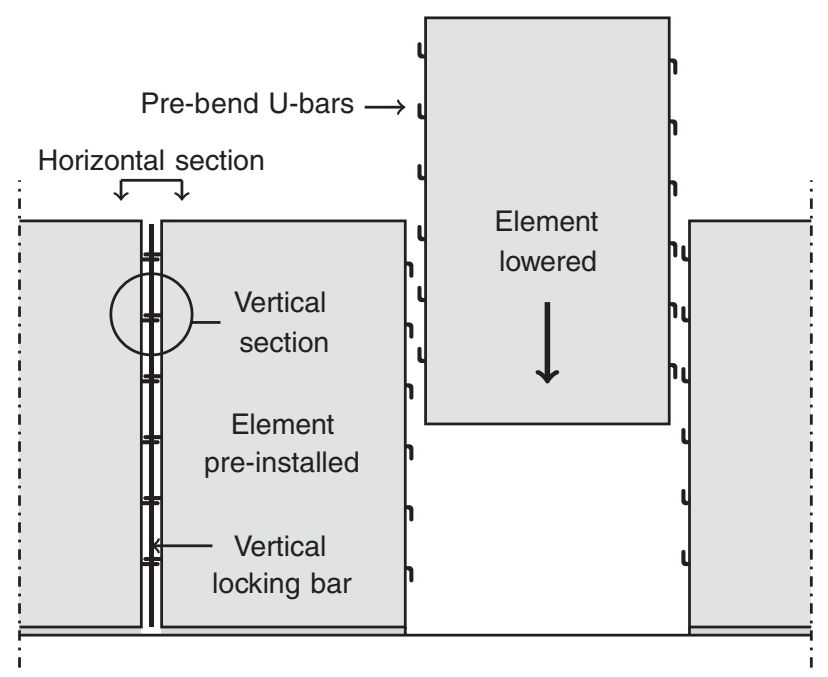

FIGURE 1 (a) Conventional shear connection design and (b) illustration of procedure for assembling of precast elements.

these connections will normally be less than that of the precast elements. ${ }^{3,4}$ In addition, the construction sequence is influenced by the design. To avoid rebar-clashing when assembling the precast panels (Figure 1b), the U-bars protruding from the precast panels have to be bent up (prior to installation of panel) and subsequently straightened again once the panel has been placed in position. This procedure imposes a limit on the cross-sectional diameter of the Ubars and hence limits the strength of the connection (normally bars with diameter $6-8 \mathrm{~mm}$ are used). The conventional shear connection is therefore not feasible for use, for example, in shear walls of tall buildings where considerable horizontal loads have to be carried.

This paper presents a new solution for the connection of precast shear wall elements. The aim of the new design is to ease the construction challenges and at the same time improve the structural performance compared to the conventional solution. Figure 2 schematically illustrates the new connection design, which differs from the conventional solution in the way the U-bar loops are oriented and in the way structural continuity is ensured in the U-bar overlaps. The joint interfaces are keyed as in the conventional solution. As illustrated in Figure 2, the loop orientation in the new solution allows for a construction-friendly installation (vertical lowering) of the precast panels, without clashing of rebars and thus without the need to pre-bend and poststraighten the U-bars, which enables U-bars with diameters larger than $8 \mathrm{~mm}$ to be used. In addition to a single longitudinal locking bar, the new design also includes the use of transverse locking bars (in the following called lacer bars) in the form of a double T-headed rebar placed inside the U-bar loops. The idea here is to utilize the double-headed rebar together with the core of mortar inside the loop as a transverse dowel that enables transfer of tension between the overlapping U-bars. Tension in the U-bars across the connection is required to ensure equilibrium when diagonal compression struts develop between the keyed joint interfaces as a result of shear loading. The double T-headed rebar is chosen because the heads provide increased anchorage of the short lacer reinforcement, which otherwise cannot be ensured using regular straight reinforcement.

To investigate the structural performance of the new connection design, an experimental program was conducted. The investigation showed that the load-displacement response of the new design is significantly more ductile than that of the conventional solution. Furthermore, the tests indicated that it is possible to obtain higher load-carrying capacities with the new design. In addition to the experimental work, this paper also presents upper-bound rigid plastic models for prediction of the critical failure mode as well as the load-carrying capacity of the new connection design. The models furnish a simple tool to optimize the geometry of the keyed joint interfaces in order to enhance the ductile behavior of the connection. 


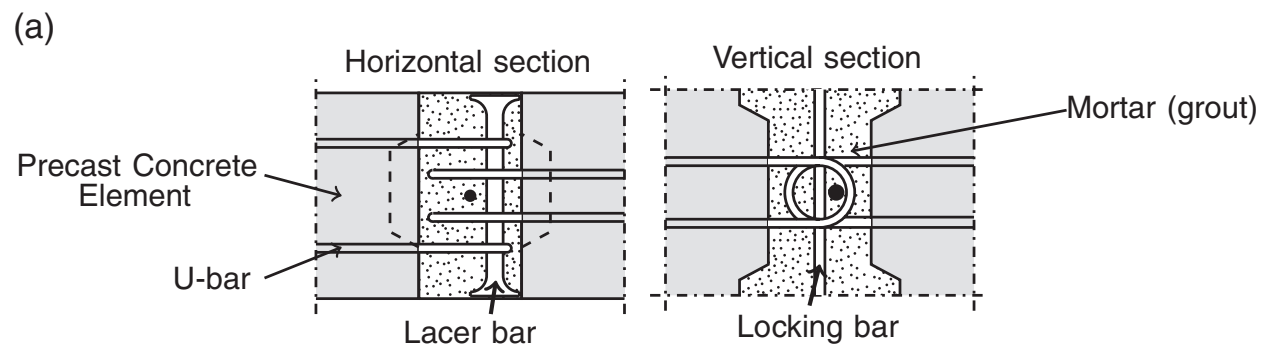

(b)

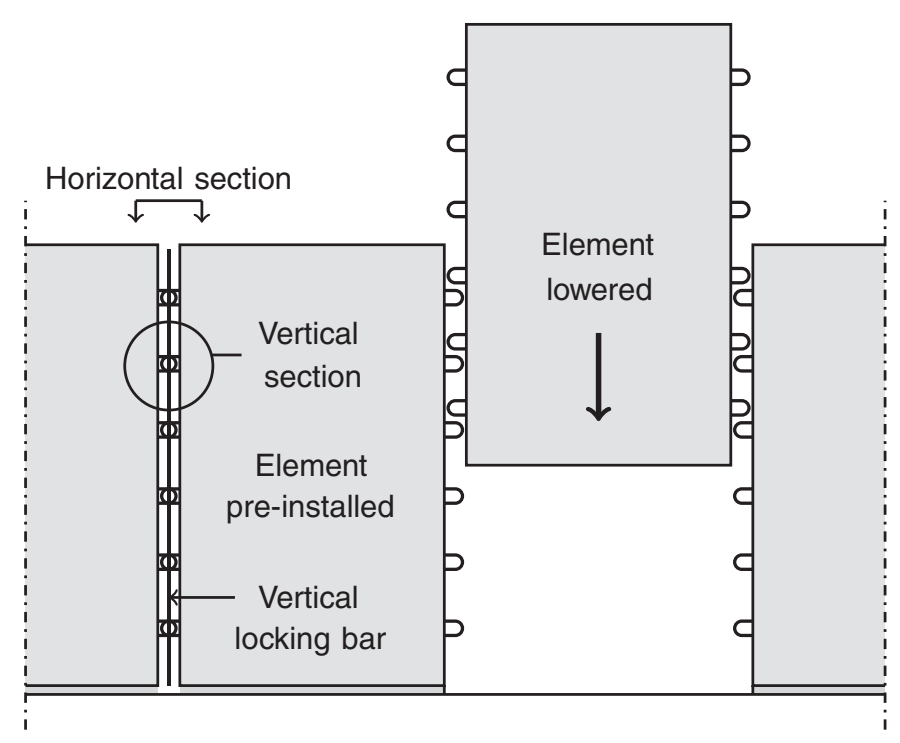

FIGURE 2 (a) New construction-friendly connection design and (b) illustration of procedure for assembling of precast elements.

\section{2 | PREVIOUS INVESTIGATIONS ON SHEAR CONNECTIONS}

With the introduction of precast element construction, the design and performance of on-site cast connections became a matter of special interest. Since the 1960s, the conventional keyed shear connection has been experimentally investigated, with the main interests being the behavior of the connection during loading, the ultimate load-carrying capacity, and the design aspects of the joint configuration. Hansen et al. ${ }^{4}$ summarized the early work on this topic in a report, which constitutes the work of the CIB commission W23A. The experimental programs that served as basis for the commission's report include the work of Halasz and Tantow, Cholewicki, Pommeret, and Fauchart and Cortini,${ }^{5-8}$ who used similar test setups as the one used in the present study. Shear tests with other test setups to investigate factors that influence the load-carrying capacity have also been published. ${ }^{9-14}$ In all investigations, regardless of testing method, it was recognized that the ultimate capacity was influenced by a number of factors, including the number of shear keys, the cross-sectional area of the keys, the strength of the grout mortar, the degree of transverse reinforcement, and the magnitude of external transverse confinement stresses.
Based on the experimental findings, a number of semiempirical formulas were suggested for the prediction of the ultimate load-carrying capacity. Current design provisions for joints between concrete cast at different times are based on the shear friction hypothesis (see, for example, the fib guide to good practice ${ }^{3}$ and the European code of practice ${ }^{15}$ ). However, other approaches can also be used. Kaneko et al. ${ }^{16,17}$ proposed a fracture mechanics approach to predict the crack formation in indented shear joints. They identified two main fracture mechanisms for shearing of keys, based on an experimental program that included plain and fiber-reinforced concrete joints. The test results were supplemented with nonlinear finite element calculations. Later, Kaneko and Mihashi ${ }^{18}$ extended the investigation by presenting an analytical model for determination of the transition between the two mechanisms. However, variations in key dimensions such as length and depth were not included in the experimental investigation.

Theoretical works based on the theory of rigid plasticity have also been proposed. Jensen ${ }^{19}$ was the first to establish an upper-bound solution for the load-carrying capacity of keyed shear joints by assuming complete shearing of the key area. These findings were later the basis for several simplified formulas, which incorporate empirical factors to fit theory with test results. This includes the 
formulas by Chakrabarti et al. ${ }^{20}$ and Abdul-Wahab and Sarsam. ${ }^{21}$ Later Christoffersen ${ }^{22}$ expanded the application of plasticity theory to include both upper- and lower-bound solutions for the shear capacity of keyed joints. Recently, Jørgensen and Hoang ${ }^{23}$ developed an upper-bound model for the failure of keyed shear joints reinforced with highstrength wire rope loops by accounting for diagonal cracks between the shear keys. Jensen, Christoffersen as well as Jørgensen and Hoang considered only a global failure mechanism with complete shearing of the keyed area. A local failure mode that involves key corner crushing has been observed by several authors. However, the problem has not been treated in depth, nor has an analytical solution been proposed.

\section{3 | EXPERIMENTAL PROGRAM}

The experimental program contained a total of 25 push-off tests. The program included a preliminary investigation of seven specimens where the performance of the conventional design, as a reference, was compared with the new design with identical geometrical joint properties. The remaining 18 specimens, Series I-IX, were subdivided into two investigations related to the geometry of the key indentation (see Figure 3). The tests were carried out in quasi-static deformation control.

\section{1 | Specimens and geometry}

The general geometry of the push-off test specimens can be seen in Figure 3 and details of geometrical and material properties are given in Table 1. Series $\mathrm{R}$ refers to reference specimens designed with a conventional reinforcement layout as illustrated in Figure 1a (however, in the reference specimens, the loops were placed outside the keyed area). Series $\mathrm{P}$ refers to pilot specimens designed with "2-on-1" vertical loop connections. This refers to a design similar to the principles shown in Figure 2a, however, in the pilot specimens, there was (for each looped connection) only one centrally placed U-bar that protruded from the precast element to the right. The cross-sectional area of this single U-bar is referred to as $A_{s}$ in Table 1. The reinforcement area in the weak side, $A_{s}$, as well as the geometry of the shear keys were identical for all specimens in Series $\mathrm{R}$ and $P$. The joints in Series $\mathrm{P}$ were not provided with longitudinal locking bars. For specimens type I-IX, "2-on-2" vertical loop connections were used (see Figure 2a). For these specimens, the area $A_{s}$ listed in Table 1 should be understood as the cross-sectional area of two U-bars. In order to eliminate the edge effect, anchorage plates were mounted at each end of the longitudinal locking bar in Series I-IX. In eight specimens (Series I-IV), the length of the keys, $L_{k}$, was varied, while the key height, $h_{k}$, was kept constant to half of the panel thickness, $t$. In the remaining

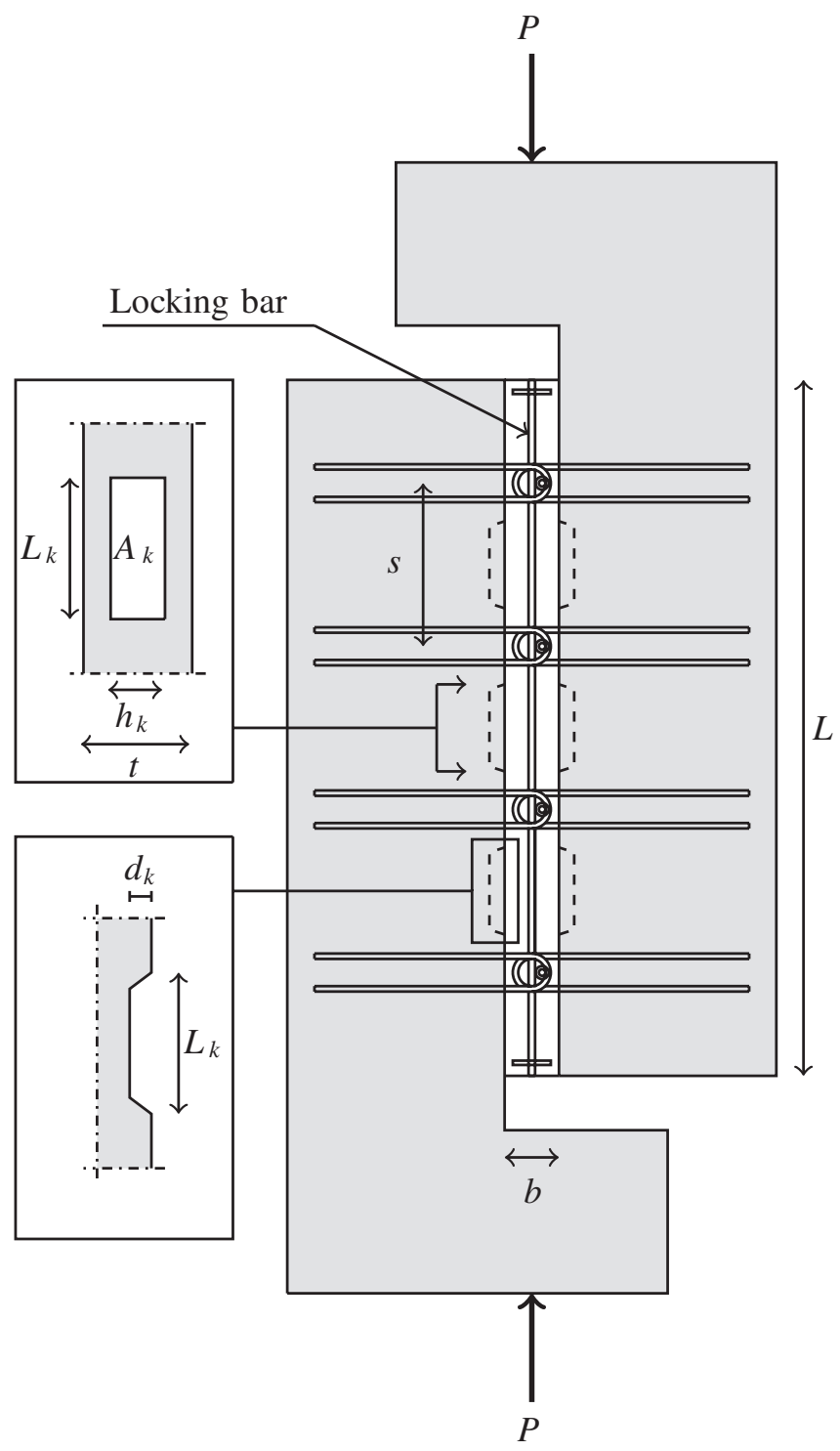

FIGURE 3 General layout of push-off test specimens, thickness equals $200 \mathrm{~mm}$ (reinforcement in precast element not shown).

ten specimens (Series V-IX), the depth of the key indentation, $d_{k}$, was varied, while the key length and the key height were kept constant, $L_{k}=140 \mathrm{~mm}$ and $h_{k}=200 \mathrm{~mm}$. Table 2 contains parameters and material properties for Series I-IX. The diameter of the lacer bar was carefully designed so that the tensile capacity of the overlapping loops would be governed by yielding of the U-bars and not crushing of the mortar. For this purpose, the calculation model for tensile capacity of U-bar loop connections developed by Jørgensen and Hoang ${ }^{24}$ was used. The double T-headed lacer bar in each loop was positioned as shown in Figure 2a to make it function as tension reinforcement in the small transverse circular mortar dowel, which ensures transfer of tension between the overlapping U-bars. Each design was tested with two replicates and the material properties were found as average values obtained from tensile tests of the steel reinforcement and compression tests of $\phi 100 \times 200 \mathrm{~mm}$ cylinders of the mortar used for casting the joints. 
TABLE 1 Geometrical parameters and strength properties of the joints in the experimental program, bold numbers indicating the specifics of the specimen

\begin{tabular}{|c|c|c|c|c|c|c|c|c|c|c|}
\hline & No. & $f_{c}^{\mathrm{a}}[\mathrm{MPa}]$ & $h_{k}[\mathrm{~mm}]$ & $L_{k}[\mathrm{~mm}]$ & $A_{k}\left[\mathrm{~mm}^{2}\right]$ & $d_{k}[\mathrm{~mm}]$ & $A_{s}\left[\mathrm{~mm}^{2}\right]$ & $P_{\mathrm{FP}}[\mathrm{kN}]$ & $P_{\mathrm{U}}[\mathrm{kN}]$ & $D_{I}[-]$ \\
\hline \multirow[t]{3}{*}{$\mathrm{R}$} & 1 & 34.6 & 85 & 160 & 13,600 & 16 & 101 & 282.43 & - & $0.42^{\mathrm{b}}$ \\
\hline & 2 & 35.7 & 85 & 160 & 13,600 & 16 & 101 & 303.80 & - & $0.59^{b}$ \\
\hline & 3 & 35.7 & 85 & 160 & 13,600 & 16 & 101 & 337.42 & - & $0.70^{\mathrm{b}}$ \\
\hline \multirow[t]{4}{*}{$\mathrm{P}$} & 1 & 38.1 & 85 & 160 & 13,600 & 16 & 101 & 344.24 & 357.45 & $1.00^{\mathrm{b}}$ \\
\hline & 2 & 38.1 & 85 & 160 & 13,600 & 16 & 101 & 347.04 & 368.12 & $0.97^{\mathrm{b}}$ \\
\hline & 3 & 42.7 & 85 & 160 & 13,600 & 16 & 101 & 342.49 & 339.97 & $0.87^{\mathrm{b}}$ \\
\hline & 4 & 42.7 & 85 & 160 & 13,600 & 16 & 101 & 331.42 & 324.49 & $0.95^{\mathrm{b}}$ \\
\hline \multirow[t]{2}{*}{ I } & 1 & 31.2 & 100 & 120 & 12,000 & 28 & 201 & 379.02 & 441.21 & $1.03^{\mathrm{c}}$ \\
\hline & 2 & 34.2 & 100 & 120 & 12,000 & 28 & 201 & 416.59 & 472.92 & $1.00^{\mathrm{c}}$ \\
\hline \multirow[t]{2}{*}{ II } & 1 & 31.2 & 100 & 140 & 14,000 & 28 & 201 & 366.40 & 463.78 & $1.06^{\mathrm{c}}$ \\
\hline & 2 & 34.2 & 100 & 140 & 14,000 & 28 & 201 & 414.46 & 462.48 & $1.00^{\mathrm{c}}$ \\
\hline \multirow[t]{2}{*}{ III } & 1 & 31.2 & 100 & 160 & 16,000 & 28 & 201 & 393.04 & 494.70 & $1.07^{\mathrm{c}}$ \\
\hline & 2 & 34.2 & 100 & 160 & 16,000 & 28 & 201 & 473.52 & 514.87 & $0.98^{\mathrm{c}}$ \\
\hline \multirow[t]{2}{*}{ IV } & 1 & 31.2 & 100 & 180 & 18,000 & 28 & 201 & 439.44 & 470.89 & $0.94^{\mathrm{c}}$ \\
\hline & 2 & 34.2 & 100 & 180 & 18,000 & 28 & 201 & 478.17 & 515.31 & $0.96^{\mathrm{c}}$ \\
\hline \multirow[t]{2}{*}{ V } & 1 & 31.2 & 200 & 140 & 28,000 & 10 & 201 & 475.24 & 488.97 & $0.97^{\mathrm{c}}$ \\
\hline & 2 & 34.2 & 200 & 140 & 28,000 & 10 & 201 & 492.86 & 535.61 & $1.04^{\mathrm{c}}$ \\
\hline \multirow[t]{2}{*}{ VI } & 1 & 30.6 & 200 & 140 & 28,000 & 16 & 201 & 527.09 & 502.55 & $0.89^{c}$ \\
\hline & 2 & 30.6 & 200 & 140 & 28,000 & 16 & 201 & 523.82 & 550.98 & $0.90^{\mathrm{c}}$ \\
\hline \multirow[t]{2}{*}{ VII } & 1 & 30.6 & 200 & 140 & 28,000 & 20 & 201 & 549.17 & 451.58 & $0.78^{\mathrm{c}}$ \\
\hline & 2 & 30.6 & 200 & 140 & 28,000 & 20 & 201 & 524.46 & 527.85 & $0.87^{\mathrm{c}}$ \\
\hline \multirow[t]{2}{*}{ VIII } & 1 & 30.6 & 200 & 140 & 28,000 & 25 & 201 & 507.05 & 528.67 & $0.92^{\mathrm{c}}$ \\
\hline & 2 & 30.6 & 200 & 140 & 28,000 & 25 & 201 & 516.97 & 545.33 & $0.92^{\mathrm{c}}$ \\
\hline \multirow[t]{2}{*}{ IX } & 1 & 30.6 & 200 & 140 & 28,000 & 28 & 201 & 526.53 & 534.19 & $0.93^{\mathrm{c}}$ \\
\hline & 2 & 30.6 & 200 & 140 & 28,000 & 28 & 201 & 527.59 & 527.07 & $0.88^{\mathrm{c}}$ \\
\hline
\end{tabular}

${ }^{a}$ Compression strength of mortar.

${ }^{b}$ Calculated using $\delta_{\max }=13 \mathrm{~mm}$.

${ }^{c}$ Calculated using $\delta_{\max }=20 \mathrm{~mm}$.

TABLE 2 Parameters kept constant for Series I-IX

\begin{tabular}{|lll}
\hline Description & Symbol & Value \\
\hline U-bar diameter & $\phi$ & $8 \mathrm{~mm}$ \\
\hline Yield strength of U-bar & $f_{y}$ & $487 \mathrm{MPa}$ \\
\hline Lacer bar diameter & $\phi_{\text {Lacer }}$ & $16 \mathrm{~mm}$ \\
\hline Yield strength of lacer bar & $f_{y, \text { Lacer }}$ & $563 \mathrm{MPa}$ \\
\hline Diameter of locking bar & $\phi_{L}$ & $12 \mathrm{~mm}$ \\
\hline Yield strength of locking bar & $f_{y L}$ & $584 \mathrm{MPa}$ \\
\hline Panel thickness & $t$ & $200 \mathrm{~mm}$ \\
\hline Internal bend diameter of loops & $D$ & $60 \mathrm{~mm}$ \\
\hline Width of joint & $b$ & $100 \mathrm{~mm}$ \\
\hline Distance between loops & $s$ & $300 \mathrm{~mm}$ \\
\hline Total length of joint & $L$ & $1,280 \mathrm{~mm}$ \\
\hline Strength of precast concrete & $f_{c, \text { element }}$ & $49.6 \mathrm{MPa}$ \\
\hline Maximum aggregate size in mortar & $d_{\text {max }}$ & $4 \mathrm{~mm}$ \\
\hline
\end{tabular}

\section{2 | Digital image correlation}

In the present investigation, digital image correlation (DIC) was used to study the relative displacements on the surface of the shear connection, including development of cracks in the joint mortar. The analysis was performed with the program Aramis. ${ }^{25}$ An example of application of the same software has been described by Pereira et al., ${ }^{26}$ who studied the cracking behavior of cement paste, mortar, concrete, and fiber-reinforced concrete. In the present study, the analysis was performed as a two-dimensional analysis using images taken with a 36.3-megapixel digital camera. The surface of the connection was spray painted with a white base layer, followed by black dots sprayed randomly to create a unique and recognizable pattern on the surface. The area covered by the Aramis analysis corresponds approximately to the area of the joint, namely $L \cdot\left(b+2 d_{k}\right)$ (see Figure 3 ). The results include the overall response of the shear connection, failure of the joint mortar between the precast elements, and also local failure of the shear keys. The results were dependent on the quality of the sprayed pattern, the light settings, and the care taken in the adjustment of the camera. The results covered only the development of cracks on the surface of the joint, however, the analysis provided invaluable information on joint behavior during loading.

\section{3 | Test results}

Figure 4 presents the general characteristics of the loaddisplacement response of the different tested connections. 
The measured displacements are relative displacements (in the longitudinal direction of the connection) between the two precast elements. Figure $4 \mathrm{a}$ can be used as a direct comparison between Series R and P, where the behavior of the reference specimens complies with previous investigations, for example, as described in detail by Hansen et al. ${ }^{4}$ The first peak also appears to be the global peak, which is immediately followed by a softening branch as the shear displacement increases. It should be noted that the response curve of specimen R1 represents a test in which the U-bar loops are pushed away from each other, whereas for specimens R2 and R3, the U-bars are pushed toward each other as the shear displacement increases. This indicates a very unfortunate property of the conventional design because the postpeak response is apparently dependent on the loading direction. It may very well be due to this fact that the postpeak behavior of the conventional design in the literature is reported both as brittle and as ductile.

Figure 4a clearly illustrates the main difference between the two designs. The loads corresponding to the first peak are comparable for specimens having identical $A_{s}$ (as given in Table 1) and identical key configuration. However, the postpeak behavior differs significantly as the new design exhibits a pronounced ductile behavior. It should be noted that the reference design (Series R), with limited ductility, can be classified as a 1-on-1 connection. The total amount of looped reinforcement in the connection may have influenced the test results (when comparing the ductility of 1-on-1 connections with the ductility of 1-on-2 and 2-on-2 connections). However, the most dominant influence on the test results is most probably due to the orientation of the U-bar loops and the presence of the transverse double-headed lacer bars. This ductile behavior is especially observed for the 2-on-2 connections, see Figure $4 \mathrm{~b}$, which presents examples of the main findings of the test Series I-IX. Before cracking, the joint behaves with

(a)

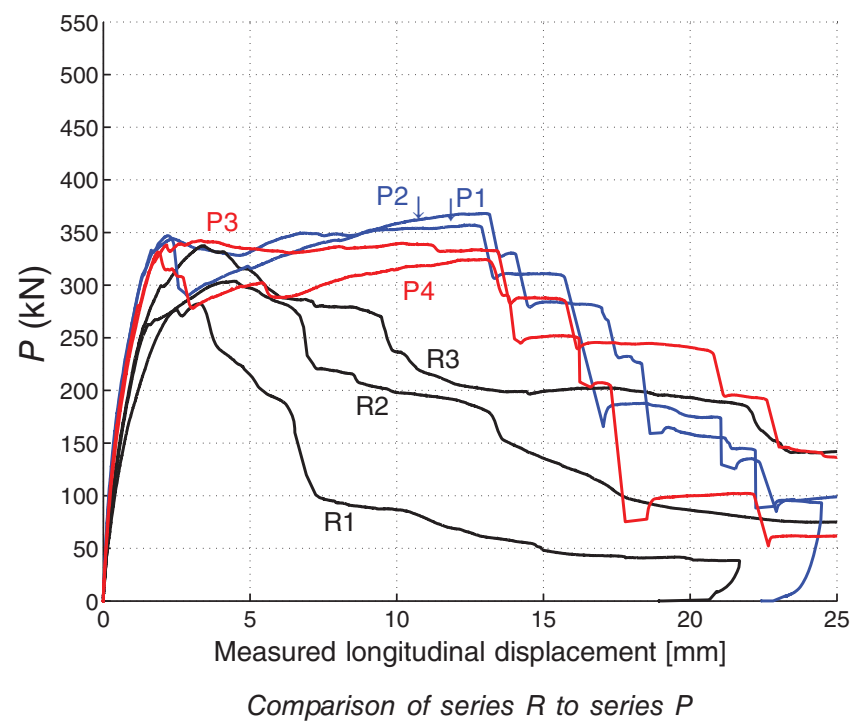

a stiffness similar to that of a monolithic wall. At a relatively small load level, cracks develop at the interface between the joint mortar and the precast element, slightly reducing the stiffness. At a higher load level, diagonal cracks between the corners of each pair of opposite shear keys start to emerge on the surface, as indications of diagonal strut action. After diagonal cracking, the stiffness of the joint decreases until the first peak on the load-displacement curve is reached, which corresponds to the value of $P_{\mathrm{FP}}$, given in Table 1 . For the new design, a drop in the response is observed after the first peak. However, as the displacement increases, the load increases again and reaches approximately the same level as the first peak. The relation between the first peak load and the ultimate load depends on the key design, which turns out to be one of the main parameters that control the failure mechanism. Rupture of the U-bars starts to take place at a displacement in the range of 12-20 mm, depending on the reinforcement configuration. The ultimate load of the joint, indicated as $P_{\mathrm{U}}$ in Table 1, is typically found at large displacements. The load level in Figure 4b is higher than the load level in Figure 4a due to the difference in the reinforcement area, $A_{s}$, per loop connection.

The first peak capacity, $P_{\mathrm{FP}}$, is governed by several factors, as identified in the above-mentioned literature. In the present study, where the tensile capacity of the loop connections was designed to be governed by U-bar yielding, the magnitude of $P_{\mathrm{FP}}$ is influenced by the geometry of the shear keys. A larger key area generally results in a higher first peak capacity. Specimen II 2 has a smaller key area compared with V2 and VIII2. This explains the lower first peak capacity for II2, however, the response after first peak shows the same tendencies as that of specimen VIII2 because both specimens had identical loop reinforcement configuration (see Figure $4 \mathrm{~b}$ ). Furthermore, it is seen that the first peak capacities of V2 and VIII2 are rather similar

(b)

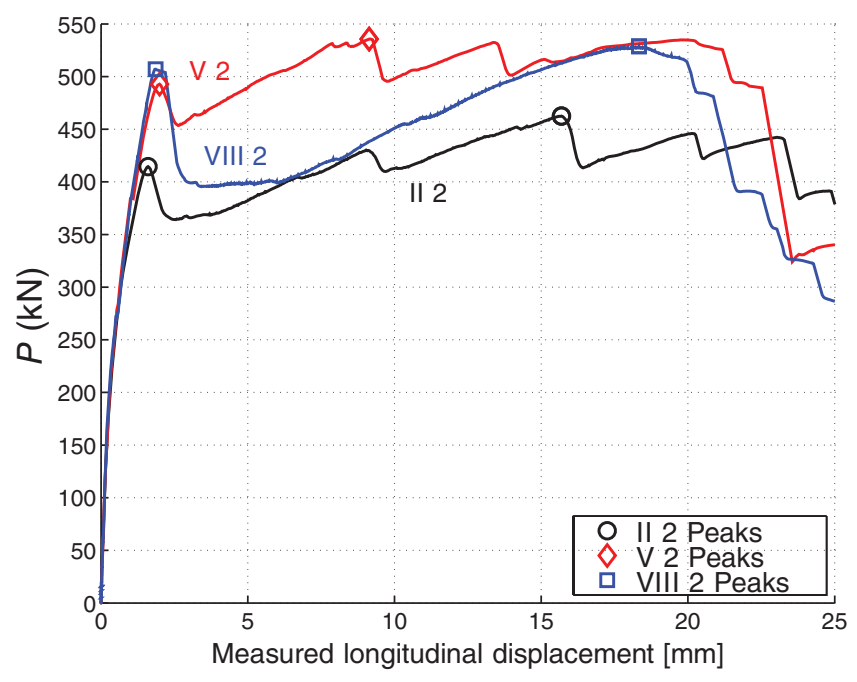

Load-displacement curves for the new design

FIGURE 4 Examples of performance of tested shear keyed joints. 
as the key areas are identical. However, after the first peak, the two specimens behave differently as the governing failure mechanisms are different (referring to Mechanisms B and $\mathrm{C}$ introduced in Figure 7). The small key depth, $d_{k}$, of specimen V2 favors shearing of the key corners, whereas the larger key depth of specimen VIII2 results in complete shearing of the key. These partly or complete key shearing failure mechanisms are in agreement with the findings for the conventional keyed joint described by Hansen et al. ${ }^{4}$ Nimityongskul and $\mathrm{Liu}^{9}$ also observed these failure mechanisms, and they interpreted the failure with partial shearing of the key corners as a consequence of an increase of the key area. A correlation between this failure mode and the depth of the shear keys has not been investigated until now.

\section{4 | Detection of failure mechanisms}

As DIC was used to monitor the cracking process on the surface of the specimen, the experimental failure mechanisms could be detected. For specimens with keys hidden in the joint, that is, Series I-IV, where $h_{k}<t$, failure of the keys was only observed indirectly as displacements at the casting joint and as diagonal cracking in the joint mortar (also see Figure 9). For specimens with keys having $h_{k}=t$, cracking of the keyed area was clear and visible when it occurred. Figure 5 shows an example of a complete shearing of a single key, where it is also observed that the preexisting diagonal crack closes almost completely as the key is sheared off. From the load-displacement response of the specimen, it appears that the observed first peak capacity was related to the shear failure of the keys. On this basis, it seems reasonable to conclude that failure of the shear keys also governs the first peak capacity of the specimens with keys hidden in the joint $\left(h_{k}<t\right)$. DIC measurements of the cracking/failure patterns have served as inspiration when developing collapse mechanisms used in the upper-bound calculations of the first peak capacity, $P_{\mathrm{FP}}$, (see Section 4).

\section{5 | Ductility of connections}

It appears from the test results that a much more ductile load-displacement response can be obtained by the new

(a)
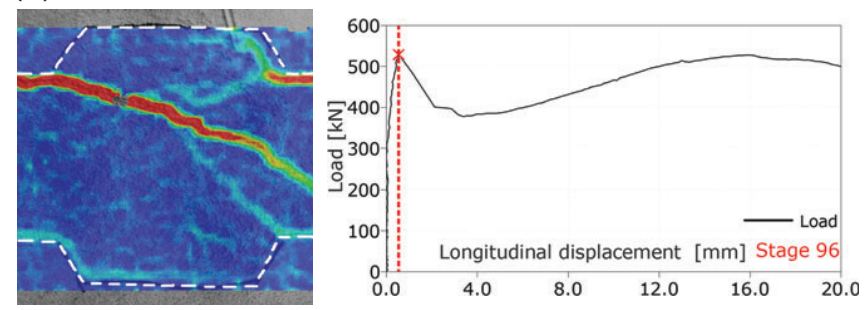

At first peak load, $P_{\mathrm{FP}}$ design compared to the conventional solution. To quantify the ductility of a shear joint, the concept of relative strain energy described by Engström ${ }^{27}$ may be considered. Engström compared the maximum resistance with the average force that can be resisted by the connection during the entire displacement spectrum. This results in an average-topeak ratio less than or equal to unity, where unity is the ideal rigid plastic behavior. In order to refine this measure, a ductility index as defined in Equation 1 is introduced:

$D_{l}=\frac{1}{\delta_{\max }-\delta_{\mathrm{FP}}} \int_{\delta_{\mathrm{FP}}}^{\delta_{\max }} \frac{P(\delta)}{P_{\mathrm{FP}}} d \delta$

The idea here is to evaluate the ability of the joint to dissipate energy in the displacement regime $\delta_{\mathrm{FP}}-\delta_{\max }$, where $\delta_{\mathrm{FP}}$ corresponds to the shear displacement at the occurrence of the first peak capacity, while $\delta_{\max }$ is the maximum shear displacement capacity of the connection. The displacement capacity, $\delta_{\max }$, can be defined as the displacement where rupture of U-bars initiates or taken as a fixed predefined value. The index, $D_{I}$, is the ratio between the dissipated energy (see the filled area in Figure 6), and the value $P_{\mathrm{FP}} \cdot\left(\delta_{\max }-\delta_{\mathrm{FP}}\right)$, which reflects the energy of a perfectly plastic connection having the capacity $P_{\mathrm{FP}}$ (see the hatched area in Figure 6). The ductility index may attain a value larger than unity. An index $D_{I}>1.0$ indicates that the joint has a robust behavior because it will be able to absorb the potential energy released when, for example, gravitational loads (applied in a load-controlled manner) reach the first peak capacity, $P_{\mathrm{FP}}$. The ductility index is highly dependent on the total shear area of the keys, $A_{k}$, as the first peak capacity increases with increasing $A_{k}$. Table 1 contains calculated values of $D_{I}$ for the tested joints. The maximum shear displacement is chosen as $13 \mathrm{~mm}$ for 2-on-1 connections and $20 \mathrm{~mm}$ for the 2-on-2 design as rupture of the reinforcement loops was observed around this magnitude of displacement. In general, the new design has a much higher $D_{I}$ index than the conventional design. The most important factor for obtaining a high ductility index is the governing failure mechanism. For practical application, it should be noted that a mechanism with key corner shearing leads to the most ductile and robust response. This issue will be further addressed in Section 4.

(b)
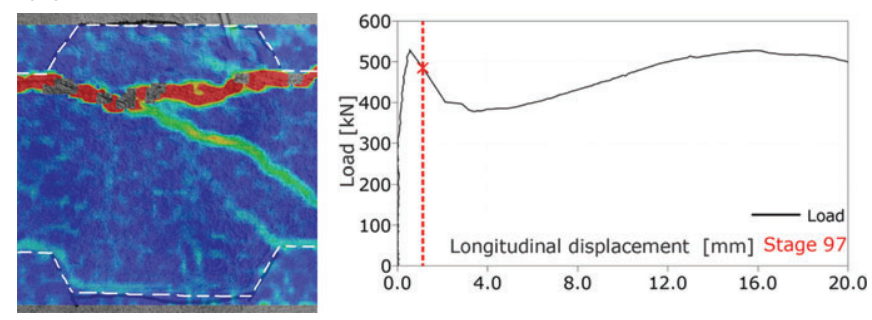

Just after first peak load, $P_{\mathrm{FP}}$

FIGURE 5 Example of complete key shearing (keys indicated with dashed lines) at first peak load, $P_{\mathrm{FP}}$, specimen IX2, $d k=28 \mathrm{~mm}$. 


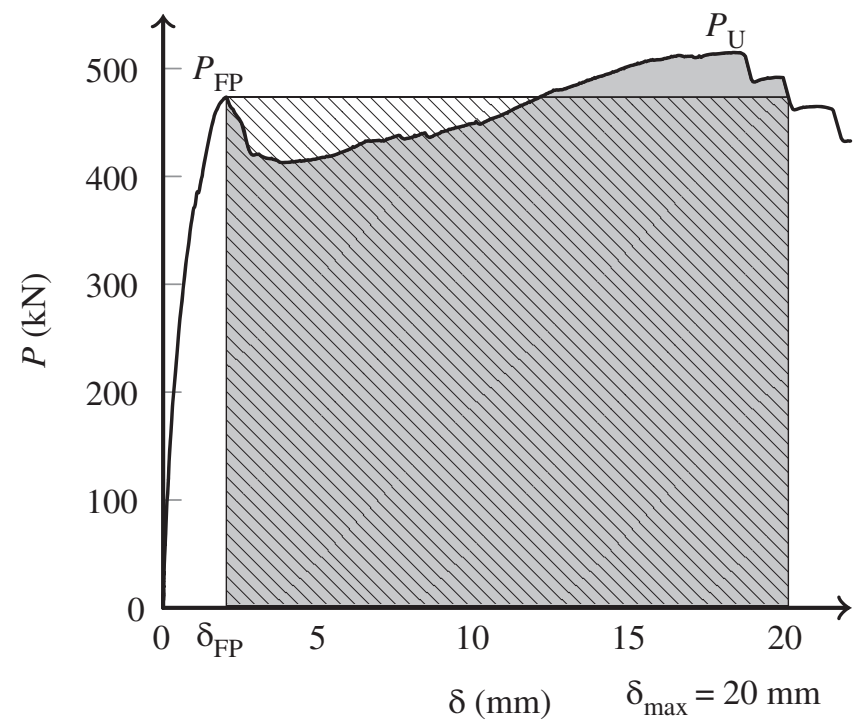

FIGURE 6 Example of calculation of the ductility index, $D_{l}$, for specimen III $2, D_{I}=0.98$.

\section{I FAILURE MECHANISMS AND UPPER-BOUND SOLUTIONS}

As demonstrated by the DIC analysis (see Section 3.4), the first peak load, $P_{\mathrm{FP}}$, is governed by failure of the shear keys. In this paper, so-called first-order rigid plastic upper-bound models will be developed to predict $P_{\mathrm{FP}}$. The ultimate load, $P_{\mathrm{U}}$, of the joints is associated with large displacements and cannot be modeled in the same simple manner. Analytical modeling of $P_{\mathrm{U}}$ would require second-order plastic analyses accounting for the change of geometry. The theoretical treatment of $P_{\mathrm{U}}$ is not a part of this paper. In the following, concrete, mortar, and reinforcing steel are assumed to be rigid perfectly plastic materials obeying the associated flow rule. Concrete and mortar are considered as modified Coulomb materials with zero tensile strength. For plain strain problems, the energy dissipated per unit area of a failure surface (yield line) may be determined as follows: ${ }^{28,29}$

$W_{A}=\frac{1}{2} \nu f_{c}(1-\sin \alpha)|\mathbf{u}|, \alpha \geq \varphi$

where $\alpha$ is the angle of the displacement vector with the yield line and $\varphi$ is the internal angle of friction. The internal angle of friction is a material property, which depends partly on the aggregate sizes and partly on the aggregate content of the matrix. ${ }^{29}$ Triaxial tests by Dahl ${ }^{30}$ indicate that $\varphi$ also depends on the confinement pressure. However, for normal strength concrete and low confinement pressures, the internal angle of friction is normally taken to be $\varphi=37^{\circ}$. For normal strength mortar with confinement pressures less than the uniaxial compressive strength of the mortar, Nielsen ${ }^{31}$ reported tests indicating an internal angle of friction around $30^{\circ}$. In this study, it is assumed that $\varphi=30^{\circ}$ for the mortar material used to grout the joints. As neither concrete nor mortar is a perfectly plastic material, an effectiveness factor $\nu$ is introduced into the theoretical solutions. ${ }^{29}$ The $\nu$-factor depends on the type of problem and is usually found by calibration with tests. For keyed joints transversely reinforced with high-strength wire loops, Jørgensen and Hoang ${ }^{23,32}$ suggest to adopt a $\nu$-formula similar to the one used for beam shear problems, ${ }^{33}$ but modified to the geometric layout of the keyed shear joint. Furthermore, the factor was adjusted to fit the shear capacity of joints cast with mortar. The $\nu$-factor for mortar joints proposed by Jørgensen and Hoang is adopted in this work:

$\nu=\frac{0.75}{\sqrt{f_{c}}}\left(1+\frac{1}{\sqrt{L_{k}}}\right) \ngtr 1.0\left(f_{c}\right.$ in MPa and $L_{k}$ in m $)$

It should be noted that the dependency of $\nu$ on $f_{c}$ and $L_{k}$ basically reflects softening effects and size effects, which in the end is also due to softening. According to Equation 3, a decrease in key length will increase the effectiveness factor, which explains why identical key areas may lead to different tested load-carrying capacities, depending on the $L_{k} / h_{k}$ ratio. In the test Series I-IX, the effectiveness factor ranges from 0.43 to 0.52 .

\section{1 | Failure mechanisms}

The load-carrying capacity, $P_{\text {cal }}$, related to a specific failure mechanism is found by solving the work equation, in which the rate of work performed by the external loads must equal the rate of internal work dissipated in the yield lines. Figure 7 shows the three basic failure Mechanisms A, B, and $\mathrm{C}$ considered in this study. The mechanisms have been identified partly on the basis of theoretical reasoning and partly with inspiration from the experimentally observed failure modes. For all three failure mechanisms, it is assumed that the precast element on the right-hand side experiences a rigid body motion described by the displacement vector $\mathbf{u}$ :

$\mathbf{u}=\left(\begin{array}{c}u_{t} \\ u_{l}\end{array}\right)$

The rate of external work is then given by:

$W_{E}=P_{\text {cal }} u_{l}$

For Mechanisms $\mathrm{A}$ and $\mathrm{B}$, it is more convenient to express the components of $\mathbf{u}$ by $|\mathbf{u}|$ and the angle $\alpha$ as follows (see Figure 7):

$u_{l}=|\mathbf{u}| \cos \alpha$

$u_{t}=|\mathbf{u}| \sin \alpha$

The rate of internal work, $W_{I}$, for the three mechanisms may in general be written as:

$W_{I}=W_{I, j}^{c}+W_{I}^{s}+W_{I}^{s L}$ 


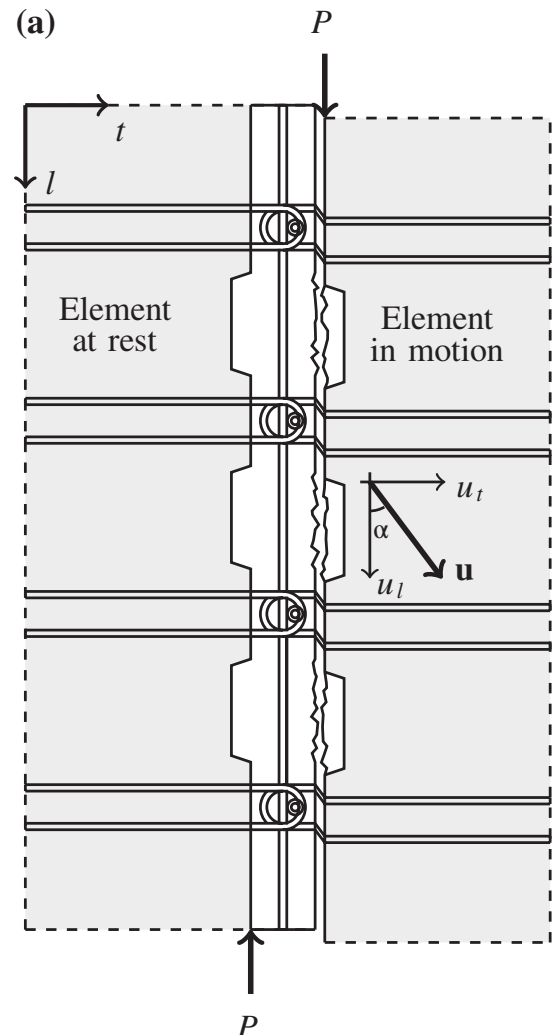

Mechanism A - Key cut off

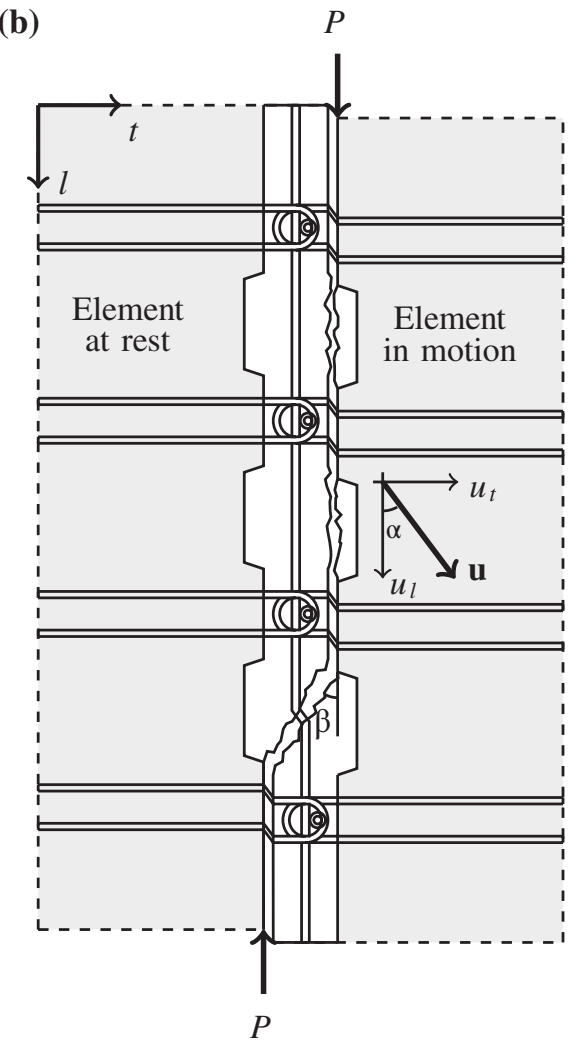

Mechanism $B(D)$ - One diagonal yield line (c)

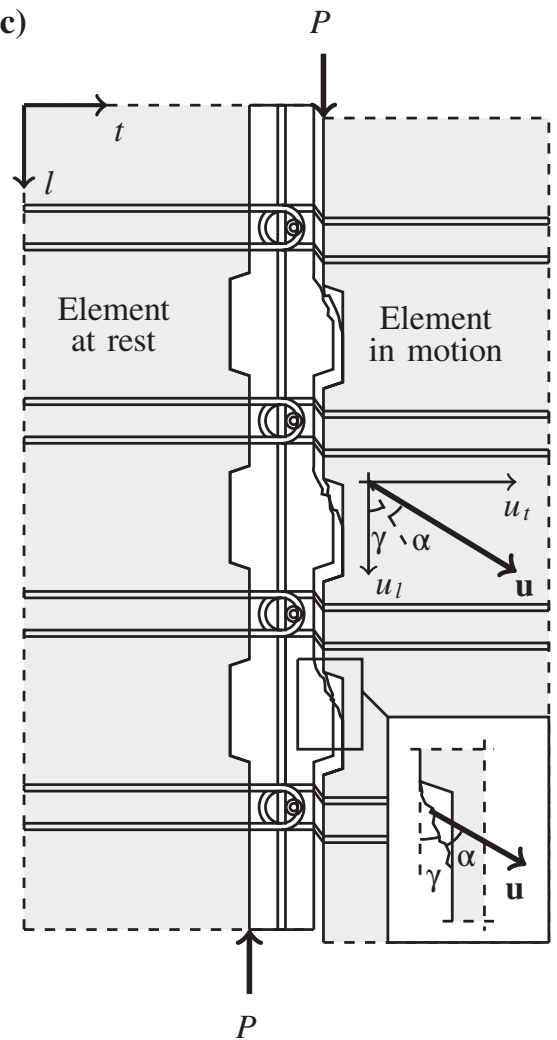

Mechanism C - Inclined key cut off

FIGURE 7 Basic failure mechanisms.

$W_{I, j}^{c}=W_{A} A_{j}$

$W_{I}^{s}=A_{s} f_{y} u_{t}$

$W_{I}^{s L}=A_{s L} f_{y L} u_{l}$

where $W_{I, j}^{c}$ is the contribution from a concrete/mortar yield line with the area $A_{j}, W_{I}^{s}$ is the contribution from the U-bars, and $W_{I}^{s L}$ is the contribution from the locking bar. Yielding of the locking bar is only required in Mechanism B.

For a general description, the following parameters are introduced and explained in Table 3:

$$
\begin{gathered}
A_{k}=L_{k} h_{k}, A_{d}=t \sqrt{b^{2}+L_{k}^{2}}, A_{i}=h_{k} \frac{d_{k}}{\sin \gamma}, \\
\tan \beta=\frac{b}{L_{k}}, \Phi=\frac{n+1}{n} \frac{A_{s} f_{y}}{A_{k} f_{c}}, \Phi_{L}=\frac{A_{s L} f_{y L}}{n A_{k} f_{c}}
\end{gathered}
$$

The parameters introduced make it easier to derive general formulas for calculation of a joint with $n$ shear keys and $(n+1)$ pairs of U-bar loops crossing the joint interface. It is convenient to define the shear capacity of the joint by an average shear stress, $\tau$, which is related to the total area of the shear keys:

$\frac{\tau}{\nu f_{c}}=\frac{P_{\mathrm{cal}}}{n A_{k} \nu f_{c}}$

\section{2 | Mechanism A: Key cut off}

To solve the work equation for Mechanism A, the rate of internal work is found as the sum of contributions from $n$ shear keys being sheared off (using $A_{j}=A_{k}$ ) and the contribution from $(n+1)$ reinforcement loops stressed to yielding:

$W_{I}=n \frac{1}{2} \nu f_{c}(1-\sin \alpha) A_{k}|\mathbf{u}|+(n+1) A_{s} f_{y} u_{t}$

An upper-bound solution is established from $W_{E}=W_{I}$ :

$\frac{\tau}{\nu f_{c}}=\frac{1-\sin \alpha}{2 \cos \alpha}+\frac{\Phi}{\nu} \tan \alpha$

TABLE 3 Symbols used in the theoretical determination of the first peak capacity

\begin{tabular}{ll} 
Symbol & Definition \\
\hline$A_{s}$ & $\begin{array}{l}\text { Reinforcement area per loop connection } \\
4 \frac{\pi}{4} \phi^{2} \text { for } 2 \text {-on-2 connections }\end{array}$ \\
& $2 \frac{\pi}{4} \phi^{2}$ for 2-on-1 connections \\
\hline$A_{k}$ & Area of one shear key \\
$A_{d}$ & Area of diagonal yield line \\
$A_{i}$ & Area of inclined yield line in a shear key \\
\hline$\Phi$ & Reinforcement degree of loop connection \\
\hline$\Phi_{L}$ & Reinforcement degree of locking bar \\
\hline$\beta$ & Slope of diagonal yield line \\
$\gamma$ & Slope of inclined yield line in a shear key \\
\hline
\end{tabular}


The optimal solution is found by minimizing the expression with respect to the angle of displacement, $\alpha$. The optimal solution is found when:

$\alpha=\arcsin \left(1-\frac{2 \Phi}{\nu}\right), \alpha \geq \varphi$

From Equation 15, it is implicitly given that the key area influences the optimal angle of displacement and thereby the capacity of the shear connection. It should be noted that the expression, with only slight change of notation, is similar to the findings of Jensen ${ }^{19}$ and Christoffersen. ${ }^{22}$

\section{3 | Mechanism B: One diagonal yield line}

For Mechanism B, the rate of internal work consists of the following contributions: $(n-1)$ times $W_{I, j}^{c}$ with $A_{j}=A_{k}$, one time $W_{I, j}^{c}$ with $A_{j}=A_{d},(n+1)$ reinforcement loops stressed to yielding, and one contribution from the locking bar stressed to yielding. The upper-bound solution is found to be:

$\frac{\tau}{\nu f_{c}}=\frac{n-1}{2 n} \frac{1-\sin \alpha}{\cos \alpha}+\frac{A_{d}}{2 n A_{k}} \frac{1-\sin (\beta+\alpha)}{\cos \alpha}+\frac{\Phi}{\nu} \tan \alpha+\frac{\Phi_{L}}{\nu}$

which has a minimum when the angle of displacement is:

$\alpha=\arcsin \left(\frac{n-1+\frac{t}{h_{k}}-2 n \frac{\Phi}{\nu}}{n-1+\frac{A_{d}}{A_{k}}}\right), \quad \alpha \geq \varphi$

From Equation 17 it can be seen that the ratio between the height of the key and the thickness of the connection influences the optimal solution for this particular failure mechanism.

\section{4 | Mechanism C: Inclined key cut off}

For Mechanism $\mathrm{C}$, the rate of internal work is found as $n$ times $W_{I, j}^{c}$ (with $A_{j}=A_{i}$ ) plus the contribution from $(n+1)$ reinforcement loops. In this mechanism, the angle between the $l$-axis and the inclined yield line is $\gamma$ (see Figure 7c). The components of the displacement vector are given by:

$u_{l}=|\mathbf{u}| \cos (\gamma+\alpha)$

$u_{t}=|\mathbf{u}| \sin (\gamma+\alpha)$

As the relationship between the transverse and the longitudinal displacement is dependent on the sum of $\gamma$ and $\alpha$, the lower limit of the condition $\alpha \geq \varphi$ is reached at lower degrees of reinforcement for this mechanism compared with Mechanisms A and B. Therefore (and to simplify), it is for this particular mechanism assumed that $\alpha=\varphi=30^{\circ}$. The optimization of the upper-bound solution is then reduced to an optimization problem involving only the angle $\gamma$, which is governed by the key dimensions and the internal angle of friction $\varphi$. The load-carrying capacity is given by: $\frac{\tau}{\nu f_{c}}=\frac{d_{k}}{2 L_{k}} \frac{1-\sin \varphi}{\sin \gamma \cos (\gamma+\varphi)}+\frac{\Phi}{\nu} \tan (\gamma+\varphi)$

The critical angle of the inclined yield line is found as:

$\gamma=\arctan \left(\frac{\cos \varphi}{\sin \varphi+\sqrt{1+\frac{\Phi}{\nu} \frac{2 L_{k}}{d_{k}} \frac{\cos \varphi}{1-\sin \varphi}}}\right)$

It appears that the internal angle of friction of the joint mortar influences the capacity significantly and to a large extent dictates, in combination with the key length to depth ratio $\left(L_{k} / d_{k}\right)$, which of the failure mechanisms $(\mathrm{A}, \mathrm{B}$, or $\mathrm{C})$ that constitutes the critical mechanism.

\section{I INFLUENCE OF KEY GEOMETRY ON FAILURE MODE}

From the derived expressions for the load-carrying capacity (Equations 14, 16, and 20) and the corresponding optimal angles of displacement, it is evident that the geometry of the joint and, in particular, the geometry of the keys, plays an important role in defining the governing failure mechanism. Figure 8 contains the results of a theoretical comparison of the load-carrying capacity related to the three basic failure mechanisms. The calculations have been performed by assuming a reinforcement arrangement similar to the one used in the experimental program Series I-IX. Figure 8a demonstrates the influence of the key height, $h_{k}$, and it appears that a higher relative key height, $h_{k} / t$, favors Mechanism B compared with a small relative key height that favors Mechanism A. Figure $8 \mathrm{~b}$ demonstrates the influence of the key depth on the failure mechanism of a joint configuration similar to the test specimens of Series V-IX, where the relative key height $h_{k} / t=1$. As expected, the smaller key depths favor Mechanism C.

The transition point (in Figure $8 \mathrm{~b}$ ) between the failure mechanisms is of particular interest because the deformation characteristics of the joint depend on the governing failure mechanism. As shown in Figure $4 \mathrm{~b}$, shearing of the key corners (specimen VII) results in a pronounced ductile behavior, which in turn leads to a high ductility index. In this context, it should be noted that the internal angle of friction for mortar is of significant interest because the transition point (see Figure 8b) partly depends on the magnitude of $\varphi$. Aramis recordings of the relative displacements at the first peak load indicate that $\varphi=30^{\circ}$ is an appropriate choice for the material used in this study, and furthermore, it is in accordance with the investigations by Nielsen. ${ }^{31}$ The recorded relative displacements were compared with the theoretical relative displacements for test specimens where the angle of displacement was predicted to be $\alpha=\varphi$. 
(a)

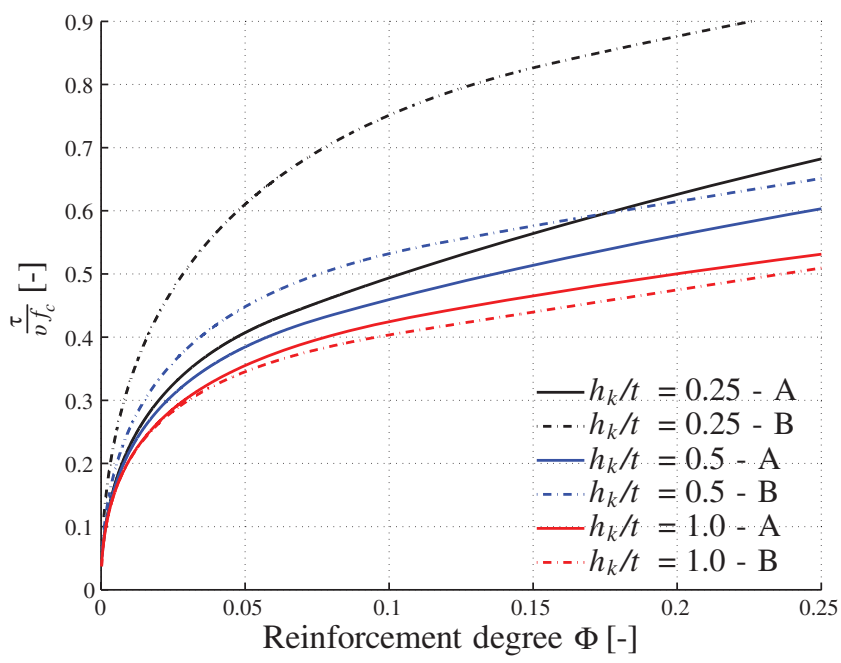

Load carrying capacity for varying relative height of key, $h_{k} / t, f_{c}=31 \mathrm{MPa}$ (b)

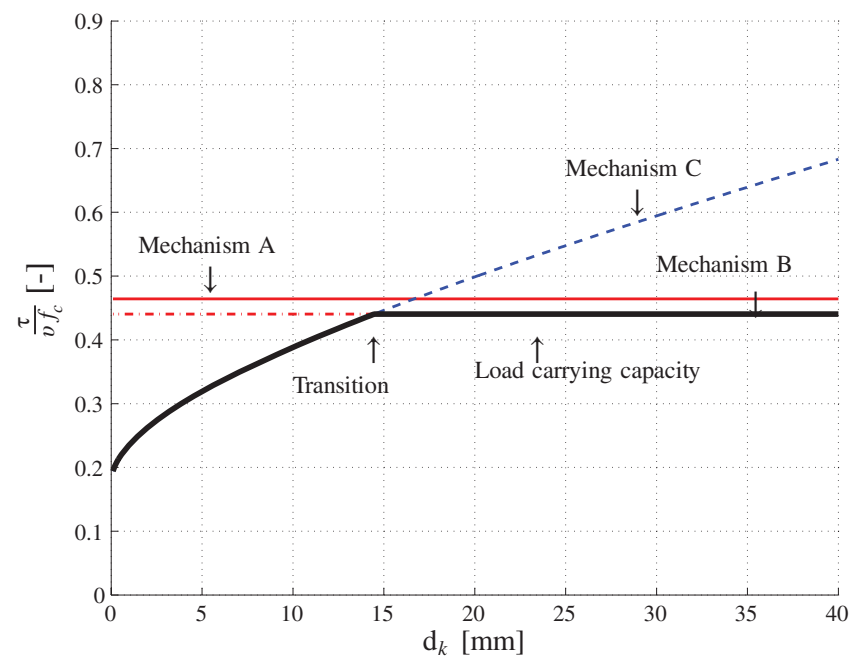

Load carrying capacity for varying key depth, $f_{c}=31$ $M P a, L_{k}=0.140 m, h_{k}=0.200 m, \Phi=0.15$

FIGURE 8 Illustrations of change in failure mechanism when changing geometry of the shear keys.

\section{I FAILURE MECHANISMS BASED ON EXPERIMENTAL OBSERVATIONS}

Based on the experimental observations, the theoretical failure mechanisms for Series I-IX are evaluated. DIC measurements have shown that a failure mechanism similar to Mechanism B, but with a relatively large crack opening in one diagonal crack prior to the first peak load, governs independently of the height of the key. Figure 9 shows Aramis recordings of the cracking process of specimen III2, which according to the theoretical calculations should reach the first peak load-carrying capacity by development of Mechanism A. It appears that diagonal cracks develop even before the first peak (see Figure 9a), and the relative displacements during failure take place in one of the existing diagonal cracks (see development from b to $\mathrm{c}$ in Figure 9). The crack opening of the diagonal cracks prior to first peak can be determined from Aramis measurements. Figure 10 shows examples of recorded crack opening of the largest diagonal crack (crack opening only in the longitudinal direction of the joint is shown). It appears that the crack opening before first peak load, $P_{\mathrm{FP}}$, is approximately $0.4 \mathrm{~mm}$, which is relatively large for mortar. This observation leads to the conclusion that the dissipation in the diagonal yield line (i.e., the mortar contribution) must be significantly reduced and thereby making a mechanism which is similar to Mechanism B more critical than Mechanism A.

In the following, two additional failure mechanisms are introduced, namely Mechanism D similar to Mechanism B (see Figure $7 \mathrm{~b}$ ), but omitting the mortar contribution from the diagonal yield line when calculating the rate of internal work, and Mechanism E based on Mechanism C, however, introducing a diagonal yield line (see Figure 11) and omitting the mortar contribution from the diagonal yield line in the calculation. For both cases, the contribution from the longitudinal locking bar is considered.

In practice, the length of a shear wall connection will at least be equal to the height of one storey, and for this reason, there will be many more shear keys in these connections as compared with the connections investigated in this study. When many shear keys are present, the significance of Mechanisms D and E will be limited. However, for the limited geometry of the test specimens, the influence of the boundary effect included in these mechanisms is relevant. The load-carrying capacity of Mechanism D is found to be:

$\frac{\tau}{\nu f_{c}}=\frac{n-1}{2 n} \frac{1-\sin \alpha}{\cos \alpha}+\frac{\Phi}{\nu} \tan \alpha+\frac{\Phi_{L}}{\nu}$

The optimal angle of displacement is given as:

$\alpha=\arcsin \left(1-\frac{2 n \Phi}{(n-1) \nu}\right), \quad \alpha \geq \varphi$

For Mechanism E (see Figure 11), the load-carrying capacity, assuming $\alpha=\varphi$, is:

$\frac{\tau}{\nu f_{c}}=\frac{n-1}{2 n} \frac{d_{k}}{L_{k}} \frac{1-\sin \varphi}{\sin \gamma \cos (\gamma+\varphi)}+\frac{\Phi}{\nu} \tan (\gamma+\varphi)+\frac{\Phi_{L}}{\nu}$

The critical angle, $\gamma$, of the inclined yield line in the keys is found as:

$\gamma=\arctan \left(\frac{\cos \varphi}{\sin \varphi+\sqrt{1+\frac{n}{(n-1)} \frac{\Phi}{\nu} \frac{2 L_{k}}{d_{k}} \frac{\cos \varphi}{1-\sin \varphi}}}\right)$

It should be noted, that Mechanisms B/D and E are only relevant for test Series I-IV, where the specimens had 2-on2 loop connections. For specimens in Series $\mathrm{P}$ with 2-on-1 connections, the asymmetric reinforcement arrangement favors Mechanism A or C. This can be seen in Figure 12, 
(a)
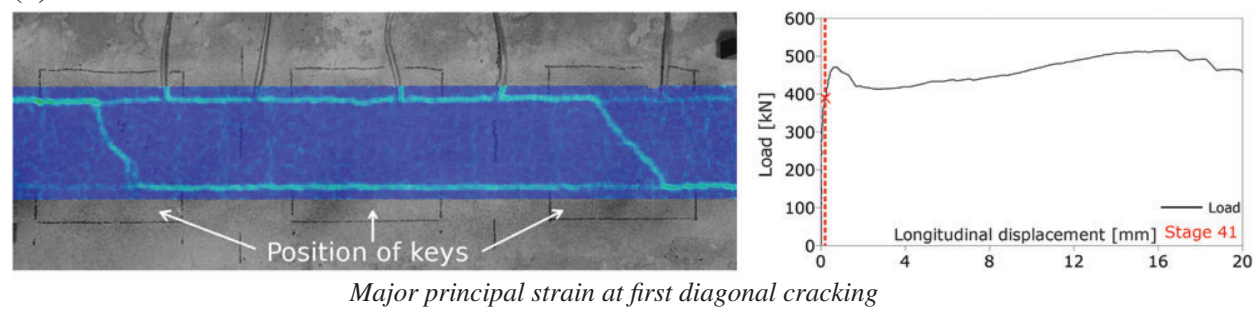

(b)

Major principal strain at first diagonal cracking
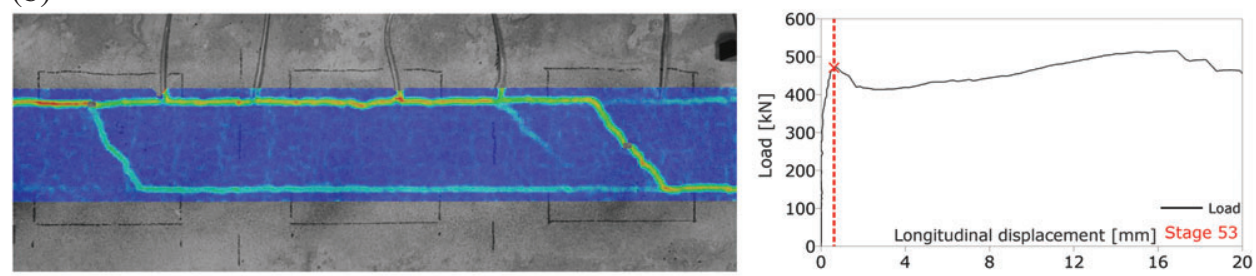

(c)

Major principal strain at first peak load
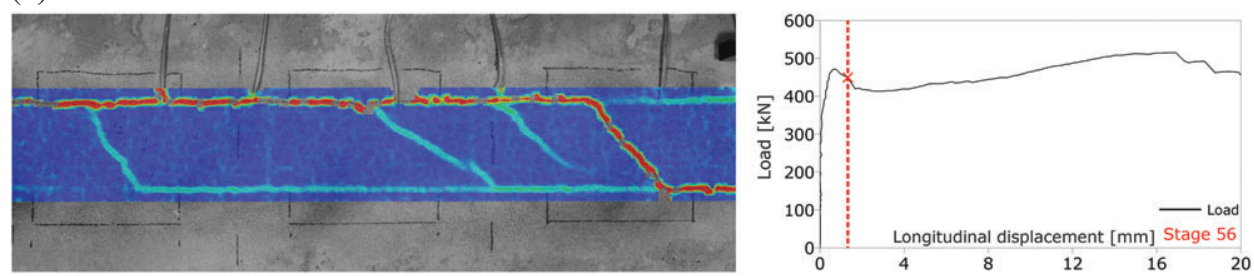

Major principal strain just after first peak

FIGURE 9 Aramis record of strain localization and cracking behavior of shear connection around first peak load, specimen III2.

(a)

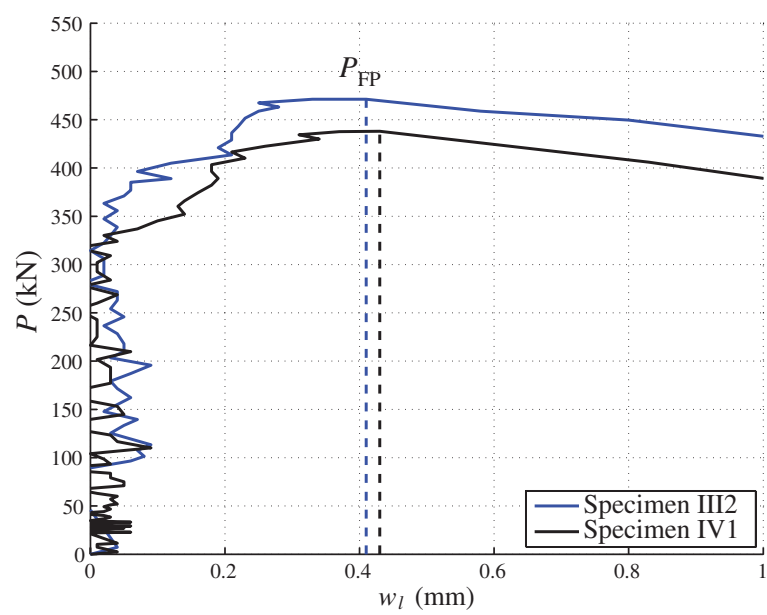

(b)

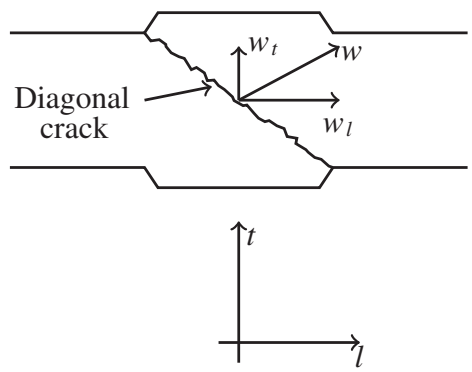

FIGURE 10 (a) Measured longitudinal crack opening in diagonal crack between shear keys and (b) definition of crack opening.

where Aramis recordings show that no diagonal cracks were present just after the first peak load.

\section{7 | COMPARISON OF TESTS WITH THEORY}

Table 4 shows the obtained experimental first peak loads as well as the theoretical determined values. For test specimens in Series I-IX, the theoretical capacity has been determined as the minimum value predicted from the five presented failure mechanisms. For specimens in Series P, only Mechanisms A and C are of interest. The yield strength of the reinforcement loops in Series $\mathrm{P}$ was $f_{y}=509 \mathrm{MPa}$, the width of the joint was $b=80 \mathrm{~mm}$, and the remaining properties are given in Tables 1 and 2.

Figures 13 and 14 show a graphical comparison where the governing failure mechanisms are identified. The 


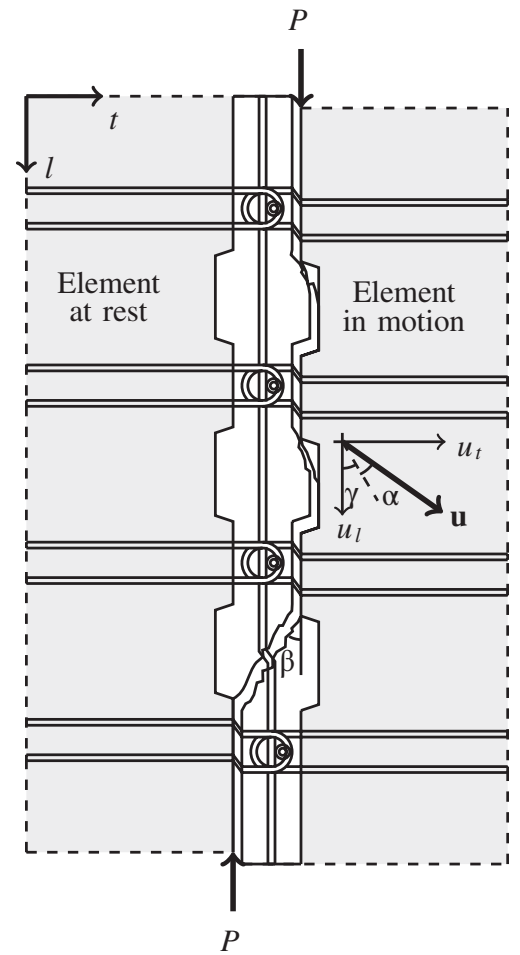

FIGURE 11 Mechanism E, based on experimental observations.

calculations are performed using the average compression strength of the grout mortar and the reinforcement strengths given in Table 2. Figure 13 shows a comparison in which the length of the shear keys, $L_{k}$, is varied and the height is kept constant at half the panel thickness. The results thereby compare with Series I-IV (Mechanism C is not critical). Figure 14 shows the comparison for varying key depths with constant key area, that is, a comparison for Series V-IX. It can be seen that the refined Mechanism D captures the behavior and predicts the load-carrying capacity of the specimens with large key depths. It can also be seen that Mechanism E explains the cracking behavior of the specimens with small key depths before Mechanism D becomes the governing mechanism for larger key depths. Table 4 also contains a summary of the observed as well as predicted failure mechanisms. If a failure mode including a diagonal crack was observed, the failure is regarded as B for the key cut off and E for the inclined key cut off. Mechanism D cannot be observed experimentally, but in fact an observed Mechanism B might relate to a theoretical Mechanism D. It can be seen from Table 4 that both Mechanisms $\mathrm{B}$ and $\mathrm{E}$ were observed in test Series VI. It should be noted
TABLE 4 Comparison of test results with theoretical values

\begin{tabular}{|c|c|c|c|c|c|}
\hline & No. & $P_{\mathrm{FP}}[\mathrm{kN}]$ & $P_{\text {cal }}[\mathrm{kN}]$ & $\frac{P_{\mathrm{FP}}}{P_{\text {cal }}}[-]$ & $\begin{array}{l}\text { Failure mechanism } \\
\text { (Observed/Predicted) }\end{array}$ \\
\hline \multirow[t]{4}{*}{$\mathrm{P}$} & 1 & 344.24 & 291.12 & 1.18 & $\mathrm{C} / \mathrm{C}$ \\
\hline & 2 & 347.04 & 291.12 & 1.19 & $\mathrm{C} / \mathrm{C}$ \\
\hline & 3 & 342.49 & 297.16 & 1.15 & $\mathrm{C} / \mathrm{C}$ \\
\hline & 4 & 331.42 & 297.16 & 1.12 & $\mathrm{C} / \mathrm{C}$ \\
\hline \multirow[t]{2}{*}{ I } & 1 & 379.02 & 395.34 & 0.96 & $\mathrm{~B} / \mathrm{A}$ \\
\hline & 2 & 416.59 & 403.29 & 1.03 & $\mathrm{~B} / \mathrm{A}$ \\
\hline \multirow[t]{2}{*}{ II } & 1 & 366.40 & 412.67 & 0.89 & $\mathrm{~B} / \mathrm{A}$ \\
\hline & 2 & 414.46 & 421.43 & 0.98 & $\mathrm{~B} / \mathrm{A}$ \\
\hline \multirow[t]{2}{*}{ III } & 1 & 393.04 & 427.62 & 0.92 & $\mathrm{~B} / \mathrm{D}$ \\
\hline & 2 & 473.52 & 433.99 & 1.09 & $\mathrm{~B} / \mathrm{D}$ \\
\hline \multirow[t]{2}{*}{ IV } & 1 & 439.44 & 438.33 & 1.00 & $\mathrm{~B} / \mathrm{D}$ \\
\hline & 2 & 478.17 & 455.20 & 1.07 & $\mathrm{~B} / \mathrm{D}$ \\
\hline \multirow[t]{2}{*}{ V } & 1 & 475.24 & 500.73 & 0.95 & $\mathrm{E} / \mathrm{E}$ \\
\hline & 2 & 492.86 & 508.21 & 0.97 & $\mathrm{E} / \mathrm{E}$ \\
\hline \multirow[t]{2}{*}{ VI } & 1 & 527.09 & 538.50 & 0.98 & $\mathrm{E} / \mathrm{D}$ \\
\hline & 2 & 523.82 & 538.50 & 0.97 & $\mathrm{~B} / \mathrm{D}$ \\
\hline \multirow[t]{2}{*}{ VII } & 1 & 549.17 & 538.50 & 1.02 & $\mathrm{~B} / \mathrm{D}$ \\
\hline & 2 & 524.46 & 538.50 & 0.97 & $\mathrm{~B} / \mathrm{D}$ \\
\hline \multirow[t]{2}{*}{ VIII } & 1 & 507.05 & 538.50 & 0.94 & $\mathrm{~B} / \mathrm{D}$ \\
\hline & 2 & 516.97 & 538.50 & 0.96 & $\mathrm{~B} / \mathrm{D}$ \\
\hline \multirow[t]{2}{*}{ IX } & 1 & 526.53 & 538.50 & 0.98 & $\mathrm{~B} / \mathrm{D}$ \\
\hline & 2 & 527.59 & 538.50 & 0.98 & $\mathrm{~B} / \mathrm{D}$ \\
\hline \multicolumn{3}{|c|}{ Mean } & & 1.01 & \\
\hline \multicolumn{3}{|c|}{ Standard deviation } & & 0.08 & \\
\hline
\end{tabular}

that a smaller value of $\varphi$ changes the transition point toward a larger key depth. However, an in-depth study of the internal angle of friction for mortar is needed to clarify the property and perhaps also the validity of the normality condition for mortar materials.

Figure 13 shows the key area as the ratio between the area of a single key compared with the joint area, $A_{t}$. The joint area is calculated using the center distance of the reinforcement loops, given as $s$ in Figure 3, and the height of the specimen, $t$. It can be seen that the average shear stress can be higher for a smaller relative key area, as expected considering softening effects in the mortar material. Generally, good agreement is found between the test results and the calculations. In Figures 13 and 14, the capacity as predicted by the Eurocode 2 formula for indented interfaces using average material strengths (tensile strength of concrete calculated by use of the EC2 method), without partial safety
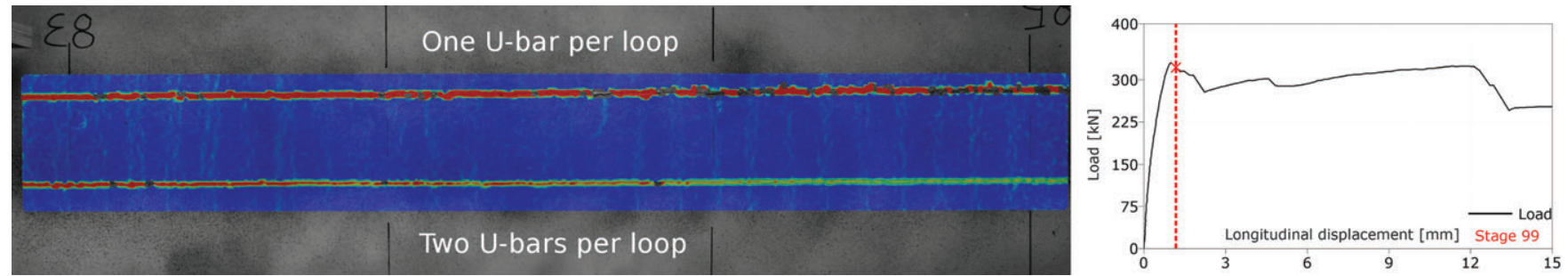

FIGURE 12 Major principal strain distribution just after first peak load, $P_{\mathrm{FP}}$, of '2-on-1' specimen (specimen P4) from pilot test series. 
$202+70$

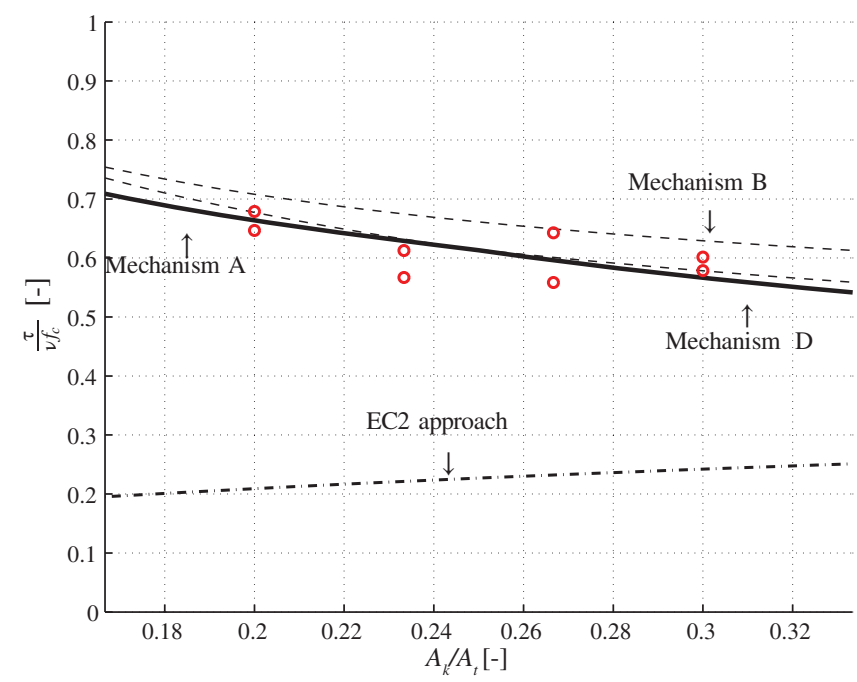

FIGURE 13 Comparison of theory with results for series I-IV, $f_{\mathrm{c}}$, average $=33.0 \mathrm{MPa}$.

factors has been included as well. It is clearly seen that the empirical formula of Eurocode 2 is too conservative when applied to the new connection design. In this context, it should be noted that the Eurocode 2 method does not take into account the specific key geometry.

\section{8 | CONCLUSIONS}

A new and construction-friendly loop connection for the assembly of precast shear wall panels has been developed and tested. The structural performance of the new connection, in terms of ductility, is superior to that of the conventional design. A ductility index has been introduced in order to evaluate and compare the performance of the developed design with that of the conventional design. For the tested designs, the first peak on the

(a)

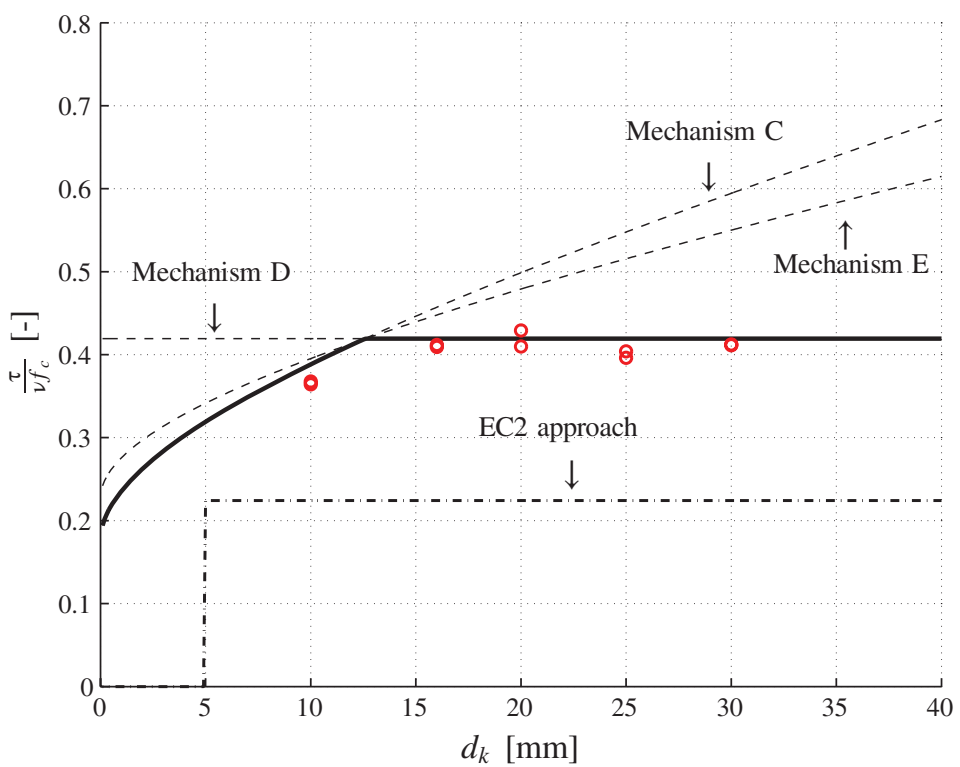

response curve has been identified as the load that causes failure of the shear keys. Theoretical failure mechanisms have been established and used to derive upper-bound plasticity solutions to calculate the first peak capacity. The failure mechanisms for the tested connections have been refined based on observations from the experiments and the results of DIC analysis.

The significance of the key dimensions has been addressed and the influence of the key height and depth on the failure mode has been outlined. The developed models predict the transition point between the two main failure mechanisms, in terms of key depth: complete key cutoff or inclined key cutoff (see Figure 14). The refined Mechanisms D and E, relevant for the limited geometry tested, captured, and explained the experimental observations. For the design of longer connections, as those found in practice, the theoretical basic Mechanisms A, $\mathrm{B}$, and $\mathrm{C}$ presented in Figure 7, will be sufficient.

It can be concluded that the new connection design is a feasible and promising practical solution that should be subjected to further investigation with the perspective of replacing the conventional solution. To adapt the new design for practical use, it is necessary to clarify a number of issues, including:

- Detailed characterization of the properties of grout mortar

- Test of a wider range of U-bar diameters and possibly a variation of the geometry of the U-bars

- Test of the tensile capacity of the connection

- Test of anchorage properties of the lacer reinforcement

- Investigation and modeling of the increase in loadcarrying capacity after the first peak

\section{ACKNOWLEDGMENTS}

The experimental program was financially supported by the Danish Association for Precast Concrete Elements and the (b)

FIGURE 14 (a) Comparison of theory with results for series V-IX, $f_{\mathrm{c}}$, average $=31.0 \mathrm{MPa}$, and (b) main failure modes. 
COWI Foundation. The test elements were produced at $\mathrm{CRH}$ Concrete and the experimental work was conducted with support from students at DTU Civil Engineering. Rune Pedersen, B.Eng., and Mads Herløv, B.Eng., contributed with test Series $\mathrm{R}$ and $\mathrm{P}$ in their bachelor thesis, J. Svejgaard, M.Sc., contributed with test Series I-IV, and L. Øvrelid, M.Sc., contributed with test Series V-IX in their master theses. Finally, the use of double-headed studs as lacer bars instead of conventional stirrups was suggested by Tim Gudmand-Høyer, Ph.D. The authors gratefully acknowledge these valuable contributions.

\section{NOTATIONS}

$A_{d} \quad$ area of diagonal yield line

$A_{i} \quad$ area of inclined yield line in a shear key

$A_{j} \quad$ area of yield line

$A_{k} \quad$ area of one shear key

$A_{s} \quad$ reinforcement area per loop

$A_{s L} \quad$ reinforcement area of locking bar

$A_{t} \quad$ area of joint

$b \quad$ width of joint

$D \quad$ internal bend diameter of loops

$D_{I} \quad$ ductility index

$d_{k} \quad$ depth of shear key

$d_{\max }$ maximum aggregate size in mortar

$f_{c} \quad$ compression strength

$f_{y} \quad$ yield strength of U-bar

$f_{y, \text { Lacer }}$ yield strength of lacer bar

$f_{y L} \quad$ yield strength of locking bar

$h_{k} \quad$ height of shear key

$L \quad$ total length of joint

$L_{k} \quad$ length of shear key

$n \quad$ number of shear keys

$P \quad$ shear load

$P_{\text {cal }} \quad$ theoretically calculated shear capacity

$P_{\mathrm{FP}} \quad$ first peak load

$P_{\mathrm{U}} \quad$ ultimate load

$s \quad$ distance between loops

$t$ panel thickness

$\mathrm{u}$ displacement vector

$u_{l} \quad$ longitudinal component of $\mathbf{u}$

$u_{t} \quad$ transverse component of $\mathbf{u}$

$w \quad$ crack opening

$w_{l} \quad$ longitudinal crack opening

$w_{t} \quad$ transverse crack opening

$W_{E} \quad$ rate of external work

$W_{I} \quad$ rate of internal work

$W_{I}^{C} \quad$ rate of internal work from concrete

$W_{I}^{s} \quad$ rate of internal work from U-bars

$W_{I}^{s L} \quad$ rate of internal work from locking bar

$\alpha \quad$ angle of displacement vector

$\beta \quad$ slope of diagonal yield line

$\delta \quad$ longitudinal displacement

$\delta_{\max } \quad$ displacement capacity
$\delta_{\mathrm{FP}} \quad$ displacement at first peak

$\gamma \quad$ slope of inclined yield line in a shear key

$\phi \quad$ U-bar diameter

$\phi_{\text {Lacer }}$ lacer bar diameter

$\phi_{L} \quad$ locking bar diameter

$\varphi \quad$ internal angle of friction

$\Phi$ reinforcement degree of loop connection

$\Phi_{L} \quad$ reinforcement degree of locking bar

$\nu \quad$ effectiveness factor

$\tau \quad$ shear stress

\section{REFERENCES}

1. Dahl KKB. Bella Sky Hotel: taking precast concrete to the limit. Struct Concr. 2014;15(4):441-447.

2. Flindt Jørgensen K. Bella Sky Hotel: exploring the potential in precast concrete design. Struct Concr. 2015;16(4):449-457.

3. fib Bulletin 43. Structural connections for precast concrete buildings, fédération international du béton ( $f i b), 2008$.

4. Hansen K, Kavyrchine M, Melhorn G, Olesen S $\varnothing$, Pume D, Schwing H. Keyed shear joints: SBI rapport 97, Technical report. Danish Building Research Institute, Copenhagen; 1976.

5. Halasz R, Tantow G. Schubfestigkeit der Vertikalfugen im Grosstafelbau. In: Berichte aus der Bauforschung, H. 39. Berlin, Germany: Verlag Wilhelm Ernst \& Sohn, Berlin; 1966.

6. Cholewicki A. Loadbearing capacity and deformability of vertical joints in structural walls of large panel buildings. Build Sci. 1971;6(9):163-184.

7. Pommeret M. Le comportement sous charges ou déformations répétées alternées des joints verticaux entre panneaux préfabriqués. Technical Report. Saint Remy les Chevreuxe, Centre expérimental de recherches et d'études du batiment et des travaux publics; 1972.

8. Fauchart J, Cortini P. Étude expérimentale de joints horizonraux entre panneaux préfabriqués pour murs de batiments. Annales de L'Institut Technique du Batiment et Des Travaux Publics, Paris, 1972.

9. Nimityongskul P, Liu HY. Vertical shear strength of joints in prefabricated loadbearing walls. Hous Sci. 1980;4(2):137-157.

10. Chakrabarti SC, Bhise NN, Sharma KN. Failure criterion of vertical shear key joints in prefabricated wall panels. Indian Concr J. 1981;55(3):63-67.

11. Abdul-Wahab HM. An experimental investigation of vertical castellated joints between large concrete panels. Struct Eng. 1986;64B(4):93-99.

12. Serrette RL, Rizkalla SH, Heuvel JS. Multiple shear key connections for load-bearing shear wall panels. PCI J. 1989;34(2):104-120.

13. Rossley N, Aziz F, Chew H, Farzadnia N. Behaviour of vertical loop bar connection in precast wall subjected to shear load. Aust J Basic Appl Sci. 2014;8(1):370-380.

14. Vaghei R, Hejazi F, Taheri H, Jaafar MS, Ali A. Evaluate performance of precast concrete wall to wall connection, APCBEE Procedia 9 (ICBEE 2013); 2014;9:285-290.

15. CEN. EN1992-1-1 Eurocode 2: Design of Concrete Structures - Part 1-1: General Rules and Rules for Buildings. 3rd ed. European Committee for Standardization, Brussels, 2004.

16. Kaneko Y, Connor JJ, Triantafillou TC, Leung CK. Fracture mechanics approach for failure of concrete shear keys. I: Theory. J Eng Mech. 1993;119(4):681-700.

17. Kaneko Y, Connor JJ, Triantafillou TC, Leung CK. Fracture mechanics approach for failure of concrete shear keys. II: Verification. J Eng Mech. 1993;119(4):701-719.

18. Kaneko Y, Mihashi H. Analytical study on the cracking transition of concrete shear key. Mater Struct. 1999;32(217):196-202.

19. Jensen BC. On the Ultimate Load of Vertical, Keyed Shear Joints in Large Panel Buildings. Technical Report. Lyngby, Denmark: Institute of Building Design, Technical University of Denmark, Lyngby; 1975.

20. Chakrabarti SC, Nayak GC, Paul DK. Shear characteristics of cast-in-place vertical joints in story-high precast wall assembly. ACI Struct J. 1988;85(1):30-45.

21. Abdul-Wahab HM, Sarsam SYH. Prediction of ultimate shear strength of vertical joints in large panel structures. ACI Struct J. 1991;88(2): 204-213. 
22. Christoffersen J, Ultimate Capacity of Joints in Precast Large Panel Concrete Buldings, Series $R$ No. 25 [Ph.D. thesis]. Lyngby: Technical University of Denmark, Department of Structural Engineering and Materials, Technical University of Denmark, Lyngby; 1997.

23. Jørgensen HB, Hoang LC. Load Carrying Capacity of Keyed Joints Reinforced with High Strength Wire Rope Loops. Proceedings of fib symposium: Concrete - Innovation and Design, Copenhagen; 2015.

24. Jørgensen HB, Hoang LC. Tests and limit analysis of loop connections between precast concrete elements loaded in tension. Eng Struct. 2013;52:558-569.

25. GOM: Aramis User Manual - Software v6.1 and higher. Braunschweig: GOM Optical Measuring Techniques; 2009.

26. Pereira EB, Fischer G, Barros JAO. Image-based detection and analysis of crack propagation in cementitious composites. In: Leung C, Wan KT, eds. Paper presented at: Proceedings of the International RILEM Conference on Advances in Construction Materials Through Science and Engineering; 2011; 1-8; HongKong, China.

27. Engström B. Ductility of Tie Connections in Precast Structures [Ph.D. thesis]. Goteborg: Chalmers University of Technology; 1992

28. Jensen BC. Nogle plasticitetsteoretiske beregninger af beton og jernbeton (English: Some Applications of Plastic Analysis to Plain and Reinforced Concrete), Report 111 [Ph.D. thesis]. Copenhagen, Denmark: Technical University of Denmark, Lyngby; 1976.

29. Nielsen MP, Hoang LC. Limit Analysis and Concrete Plasticity. 3rd ed. CRC Press, Taylor \& Francis Group, Boca Raton, Florida, US; 2011.

30. Dahl KKB. A Failure Criterion for normal and High Strength Concrete, Technical Report. Lyngby, Denmark: Technical University of Denmark; 1992.

31. Nielsen CV. Triaxial behavior of high-strength concrete and mortar. ACI Mater J. 1998;95(2):144-151.

32. Jørgensen HB. Strength of Loop Connections between Precast Concrete Elements [Ph.D. thesis]. Denmark: University of Southern Denmark, Department of Technology and Innovation, Odense; 2014.

33. Zhang J-P. Diagonal cracking and shear strength of reinforced concrete beams. Mag Concr Res. 1997;49(178):55-65.

\section{AUTHOR'S BIOGRAPHIES}

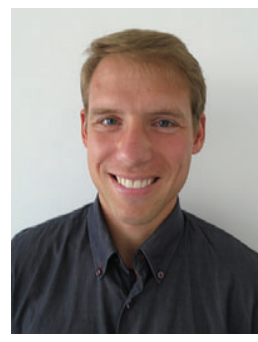

Jesper Harrild Sørensen

M.Sc., PhD student

Department of Civil Engineering

Technical University of Denmark

Brovej, Building 118

2800 Kgs. Lyngby,

Denmark

jhaso@byg.dtu.dk

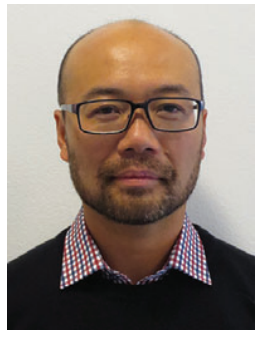

Linh Cao Hoang

Professor, $\mathrm{PhD}$

Department of Civil Engineering

Technical University of Denmark

Brovej, Building 118

2800 Kgs. Lyngby,

Denmark

linho@byg.dtu.dk

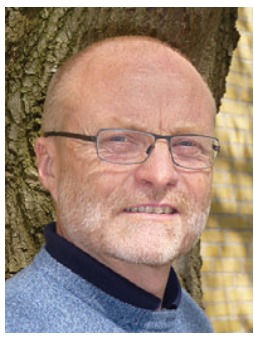

John Forbes Olesen

Associate Professor, $\mathrm{PhD}$

Department of Civil Engineering

Technical University of Denmark

Brovej, Building 118

2800 Kgs. Lyngby,

Denmark

jfo@byg.dtu.dk

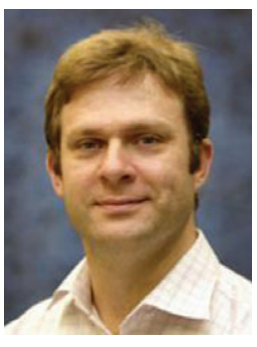

Gregor Fischer

Associate Professor, $\mathrm{PhD}$

Department of Civil Engineering

Technical University of Denmark

Brovej, Building 118

2800 Kgs. Lyngby,

Denmark

gf@byg.dtu.dk

How to cite this article: Sørensen JH, Hoang LC, Olesen JF, Fischer G. Test and analysis of a new ductile shear connection design for RC shear walls. Structural Concrete. 2017;18:189-204. https://doi.org/10.1002/ suco.201600056 